\title{
Nuclear and Optical Analyses of MOS Devices
}

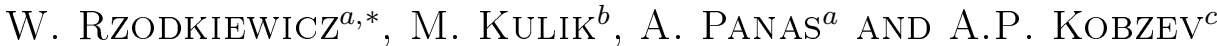 \\ ${ }^{a}$ Institute of Electron Technology, al. Lotników 32/46, 02-668 Warsaw, Poland \\ ${ }^{b}$ Institute of Physics, Maria Curie-Skłodowska University, pl. M. Curie-Skłodowskiej 1, 20-031 Lublin, Poland \\ ${ }^{c}$ Frank Laboratory of Neutron Physics, Joint Institute for Nuclear Research, 141980 Dubna, Russia \\ The characteristic dome-like shape distribution of electric parameters (with the biggest values in the middle \\ and the lowest values in the corners of the gate) has been observed in our investigations. Taking the results of \\ the papers into account, the following hypothesis was drawn: the shape distribution of electrical parameters has \\ been caused by the irregular shape of stress distribution under the metal gate. To prove or deny the assumed \\ hypothesis, a lot of investigations on stress and strain in MOS structures are being performed. The study of the \\ atomic composition of electronic components constitutes the starting point of their characterization. Therefore, in \\ this paper, we present experimental results of hydrogen, oxygen, aluminum, silicon, and copper concentrations in \\ MOS structures carried out by the Rutherford backscattering spectrometry and elastic recoil detection methods. \\ These techniques allow inter alia determination of silicon and oxygen content as a function of the position $x$ on \\ a wafer. On the basis of depth profile elastic recoil detection measurements performed on $\mathrm{Al}$ and $\mathrm{AlSiCu}$ gates, \\ a much larger hydrogen content in the surface layer for MOS structure with Al gate was confirmed. Copper atoms \\ were detected only in the $\mathrm{AlSiCu}$ gate.
}

DOI: 10.12693/APhysPolA.123.851

PACS: 82.80.Yc, 78.20.Ci, 07.60.Fs, 85.30.-z

\section{Introduction}

The metal-oxide-semiconductor (MOS) structure stands for the most important building block in the ultra-large-scaled-integrated circuits (ULSIC) [1]. As MOS device sizes diminish, the gate oxide reduces to a thickness of $10 \mathrm{~nm}$ and less, resulting in heavy difficulties in manufacturing an oxide layer in this thickness range with the desired dielectric and reliability attributes. In connection with the above, mechanical strain-related problems have become essential for semiconductor technology processes. In our investigations, the characteristic dome-like shape distribution of electric parameters (with the biggest values in the middle and the lowest values in the corners of the gate) has been observed [2-4]. Taking the results of the papers into account, the following hypothesis was drawn: irregular shape distribution of electrical parameters has been caused by the irregular shape of stress distribution under the metal gate. To prove or deny the assumed hypothesis, a lot of investigations on stress and strain in MOS structures are being performed. In the paper, we plan to confirm or exclude the effect of distribution of some elements concentration on the local distribution of stress in MOS devices.

In the production of MOS devices, post-oxidation exposure to hydrogen appears either advisable or inevitable during a variety of processing steps [5]. Hydrogen can be present at serious concentrations even in thermal oxides grown in nominally pure oxygen. Various analysis techniques are preferable for detection of the total hydrogen content in solids. Among other methods, the elastic recoil

*corresponding author; e-mail: rzodki@ite.waw.pl detection (ERD) technique in reflection and transmission mode has also been used during the last decades [6-9].

\section{Experimental}

Several wafers with two MOS structures on each were investigated. Specific mask was designed. To this goal, two one-side polished three inch silicon substrates of $p$-type conduction and $\langle 100\rangle$ orientation were used. In order to produce the above mentioned MOS structures, the silicon wafers were subjected to the following processes:

1. Thermal oxidation Hydrox (in water vapor) to a thickness of $500 \mathrm{~nm}$;

2. Photolitography using an appropriate mask for the oxide;

3. Photolitography, wet etching of the oxide;

4. Removal of emulsion;

5. Thermal oxidation Hydrox (in water vapor) to a thickness of $60 \mathrm{~nm}$;

6. Metallization - front side, $\mathrm{Al}$ on the wafer no. $1 / \mathrm{AlSi}_{1 \%} \mathrm{Cu}_{0.5 \%}$ on the wafer no. $3 /$ to the thickness $c a .20 \mathrm{~nm}$;

7. Photolitography of metallization using an appropriate mask for metal;

8. Photolitography, etching of $\mathrm{Al}$ on the wafer no. 1/ etching of $\mathrm{AlSi}_{1 \%} \mathrm{Cu}_{0.5 \%}$ on the wafer no. $3 /$ on wet;

9. Metallization - back side, $\mathrm{Al}$ to the thickness $c a$. $500 \mathrm{~nm}$;

10. Annealing at $450{ }^{\circ} \mathrm{C}$ for 20 min in $\mathrm{H}_{2}$ atmosphere. 
Using the above technological procedure, the obtained values of oxide thickness under the gate material and beyond the gate area were $c a .60 \mathrm{~nm}$ and $c a .500 \mathrm{~nm}$, respectively. Dimension of the gates for the nuclear studies were following: $15 \mathrm{~mm} \times 55 \mathrm{~mm}$. The investigated wafers were divided into the $2 \mathrm{~cm}$ width strips.

The Rutherford backscattering spectrometry (RBS) and ERD measurements were carried out simultaneously. The depths profiles of hydrogen and the effect of diffusion were investigated by the ERD and RBS methods at room temperature. The energy of incident $\mathrm{He}^{+}$ions was $2297.0 \mathrm{keV}$, the scattering angle $\theta=135^{\circ}$, and the incidence angle $\phi$ of the ion beam on the studied surfaces was $75^{\circ}$ in the RBS experiment. At the same time recoiled hydrogen ions were collected through semiconductive detector. The angle between the $\mathrm{He}^{+}$beam and the direction of collected hydrogen ions was $30^{\circ}$. These measurements were carried out on the Van de Graaff accelerator EG5 at JINR, Dubna. For optical characterization, variable-angle spectroscopic ellipsometer of J.A. Woollam Company was applied. The range of used wavelengths was from $250 \mathrm{~nm}$ to $1000 \mathrm{~nm}$ with a $5 \mathrm{~nm}$ step. Ellipsometric measurements were performed at three angles of incidence: 65,70 , and 75 degrees.

\section{Results and discussion}

The typical RBS and ERD spectra collected on $\mathrm{AlSi}_{1 \%} \mathrm{Cu}_{0.5 \%}$ gate of the MOS structure are presented in Fig. 1a and b. These curves were measured at the same time and in the same place on metallic part of the MOS structure. Using the results of the RBS and ERD measurements, the relative atomic distributions of elements in 6 layers (starting from a top) of the MOS structure were obtained (Table I) with a help of the SIMNRA code [10]. Two bands connected with oxygen at energy about $600 \mathrm{keV}$ and $700 \mathrm{keV}$ are observed in Fig. 1a. They correspond, respectively, to scattering of $\mathrm{He}^{+}$ions on oxygen: in a $\mathrm{SiO}_{2}$ layer and on the $\mathrm{Al}_{2} \mathrm{O}_{3}$ surface. In Fig. 1a the minimum at about $900 \mathrm{keV}$ is observed, due to silicon in $\mathrm{SiO}_{2}$. The sharp border near $1100 \mathrm{keV}$ is connected with $\mathrm{He}^{+}$scattering on $\mathrm{Al} \mathrm{nu}-$ clei in the $\mathrm{Al}_{2} \mathrm{O}_{3}$ layer. The $\mathrm{Cu}$ atoms were detected in the metallic layer (see inset of Fig. 1a). The band of unknown origin near the energy $1750 \mathrm{keV}$ was also observed. This band can be probably assigned to elements like $\mathrm{Nd}$, introduced as technological contamination during the fabrication process.

TABLE I

Atomic concentration of elements in near-surface layers of MOS structure.

\begin{tabular}{c|c|c|c|c|c|c}
\hline \hline \multirow{2}{*}{ Layer } & Layer thickness & \multicolumn{5}{|c}{ Elements [\%] } \\
\cline { 3 - 7 } & {$\left[1 \times 10^{15}\right.$ atoms $\left./ \mathrm{cm}^{2}\right]$} & $\mathrm{H}$ & $\mathrm{O}$ & $\mathrm{Al}$ & $\mathrm{Si}$ & $\mathrm{Cu}$ \\
\hline 1 & 160 & 20.2 & 40.0 & 39.5 & 0.0 & 0.3 \\
2 & 1300 & 0.2 & 5.5 & 94.0 & 0.0 & 0.3 \\
3 & 445 & 0.3 & 64.7 & 0.0 & 35.0 & 0.0 \\
4 & 100 & 0.3 & 52.7 & 0.0 & 47.0 & 0.0 \\
5 & 1000 & 0.3 & 0.0 & 0.0 & 99.7 & 0.0 \\
6 & 3000 & 0.0 & 0.0 & 0.0 & 100.0 & 0.0
\end{tabular}
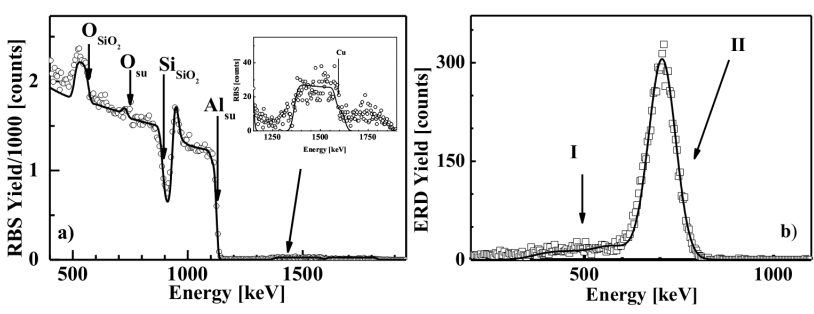

Fig. 1. RBS (a) and ERD (b) spectra collected from MOS structure with incident $2297 \mathrm{keV} \mathrm{He}^{+}$ions; solid line - the best fit, symbols represent RBS and ERD data. $\mathrm{Al}_{\mathrm{su}}$ and $\mathrm{O}_{\text {su }}$ correspond to $\mathrm{Al}$ and $\mathrm{O}$ surface atoms.

In Fig. $1 b$ the ERD spectrum of the MOS structure is shown, composed of two bands (I, II). The weak band I at the energy about $500 \mathrm{keV}$ is due to hydrogen atoms, probably from a transient layer between the metal and $\mathrm{SiO}_{2}$ layers. The strong band II at $700 \mathrm{keV}$ is referred to atoms of hydrogen from the near-surface layers of oxidized aluminum.

It is observed that the copper atoms exist only in the same layers of the MOS structure as Al atoms (Table I). The concentration of $\mathrm{Cu}$ is constant but that of aluminum increases with depth. In the first layer of the MOS structure there are also atoms of oxygen ( $40 \%$ concentration) and hydrogen $(20 \%)$. Their presence can be attributed to the process of oxidation of the metallic surface and adsorption of hydrogen. Hydrogen is also detected in the layers $(2-5)$ of the MOS structure (Table I). The border is sharp between the metal $(1,2)$ and the $\mathrm{SiO}_{2}$ layers $(3,4)$.
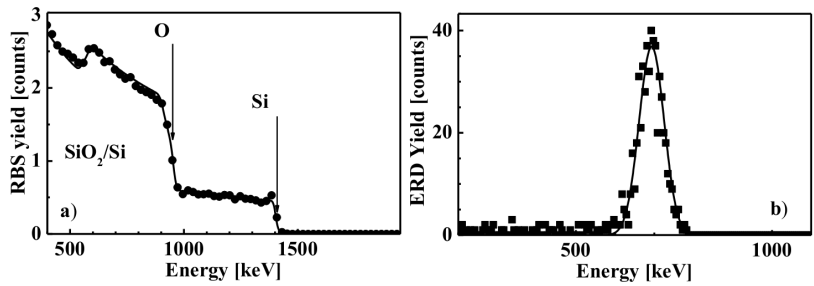

Fig. 2. RBS (a) and ERD (b) typical spectra collected from the $\mathrm{SiO}_{2} / \mathrm{Si}$ structure with incident $2297 \mathrm{keV} \mathrm{He}^{+}$ ions; solid line - the best fit, symbols represent RBS and ERD data.

TABLE II

Atomic concentration of elements in $\mathrm{SiO}_{2} / \mathrm{Si}$ structure.

\begin{tabular}{c|c|c|c|c}
\hline \hline \multirow{2}{*}{ Layer } & Layer thickness & \multicolumn{3}{|c}{ Elements [\%] } \\
\cline { 3 - 5 } & {$\left[1 \times 10^{15}\right.$ atoms $\left./ \mathrm{cm}^{2}\right]$} & $\mathrm{H}$ & $\mathrm{O}$ & $\mathrm{Si}$ \\
\hline 1 & 350 & 6.0 & 62.0 & 32.0 \\
2 & 2800 & 0.0 & 68.0 & 32.0 \\
3 & 200 & 0.0 & 35.0 & 65.0 \\
4 & 3500 & 0.0 & 0.0 & 100.0
\end{tabular}

The same study was performed for $\mathrm{SiO}_{2} / \mathrm{Si}$. The results of these investigations are shown in Fig. 2 and Table II. The sharp borders at the energy of $950 \mathrm{keV}$ and 
$1400 \mathrm{keV}$ are observed in the RBS spectrum (Fig. 2a), indicating a good surface quality of $\mathrm{SiO}_{2}$ layers. From these data a number of incidence particles in the solid angle have been obtained. This value is required for fitting the ERD results with a theoretical curve. The measured and calculated ERD spectra are presented in Fig. 2b. Hydrogen was detected at a concentration of $6 \%$ in the top (1) layer of the $\mathrm{SiO}_{2} / \mathrm{Si}$ structure (Table II).

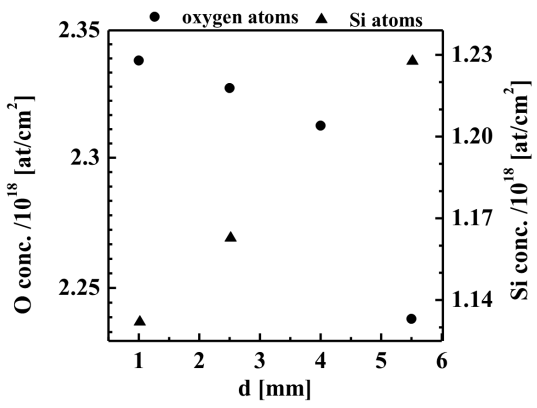

Fig. 3. Distribution of silicon and oxygen concentration in MOS structure along a distance from metallic edge of the gate as determined from RBS measurements.

Additionally, oxygen and silicon concentrations along the gate material (along the longest edge of the gate rectangle) from the edge to the middle of the gate were determined. These results are shown in Fig. 3. Concentration of elements as a function of the distance $d$ from the metallic edge is given in real values. Simultaneously oxygen concentration decreases and silicon concentration increases along the distance from the $\mathrm{Al}$ gate edge. It can be connected with the increase in refractive index. This probably leads to the increase in stress in the oxide layer under the gate with maximum value in the middle of the gate.

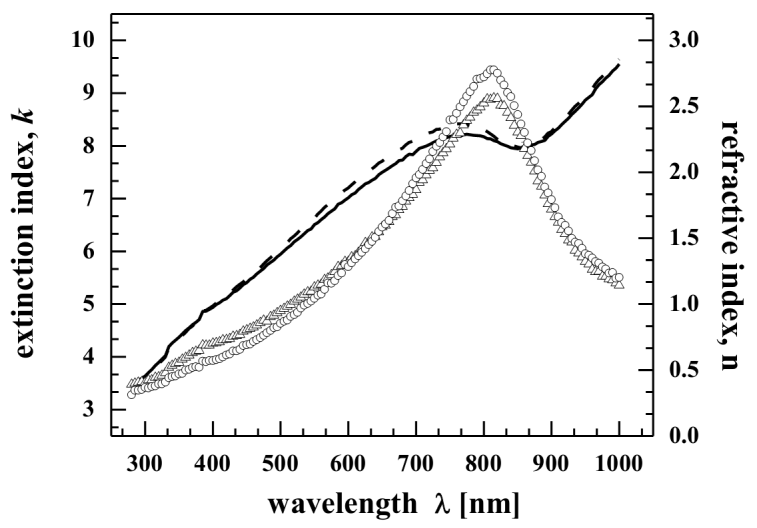

Fig. 4. Spectra of refractive and extinction indices for $\mathrm{Al}$ (circles and dashed line, respectively) and $\mathrm{AlSi}_{1 \%} \mathrm{Cu}_{0.5 \%}$ (triangles and solid line, respectively) gate materials.

In Fig. 4 optical constants spectra obtained by variable-angle spectroscopic ellipsometry (VASE) for both $\mathrm{AlSi}_{1 \%} \mathrm{Cu}_{0.5 \%}$ and $\mathrm{Al}$ gate materials are presented. The copper admixture has caused a slight decrease of optical parameters for the $\mathrm{AlSi}_{1 \%} \mathrm{Cu}_{0.5 \%}$ alloy gate in comparison to a pure aluminum gate. Similar degradation mechanism of MOS structures was also observed in the papers [11, 12], particularly in electrical characteristics of MOS devices.

\section{Summary and conclusion}

On the oxide surface the existence of hydrogen was detected (as a result of thermal oxidation in Hydrox, $\mathrm{OH}$ groups can be created). $\mathrm{H}$ atoms were also found in all layers of the MOS structure. It was observed that copper atoms exist only in the same layers of the MOS structure as $\mathrm{Al}$ atoms. The concentration of $\mathrm{Cu}$ is constant but that of aluminum increases with depth. The decrease of oxygen concentration accompanies the increase of silicon concentration along the distance from the metallic gate edge. It can be connected with the increase in refractive index. This probably leads to the increase in stress in the oxide layer under the gate with a maximum value in the middle of the gate.

\section{References}

[1] C.-C. Hong, J.-G. Hwu, Appl. Phys. Lett. 79, 3797 (2001).

[2] H.M. Przewłocki, A. Kudla, D. Brzezinska, H.Z. Massoud, Microelectron. Eng. 72, 165 (2004).

[3] A. Kudla, H.M. Przewłocki, L. Borowicz, D. Brzezinska, W. Rzodkiewicz, Thin Solid Films 450, 203 (2004).

[4] H.M. Przewłocki, A. Kudla, K. Piskorski, D. Brzezinska, Thin Solid Films 516, 4184 (2008).

[5] I.J.R. Baumvol, F.C. Stedile, C. Radtke, F.L. Freire Jr, E. Gusev, M.L. Green, D. Brasen, Nucl. Instrum. Methods Phys. Res. B 136, 204 (1998).

[6] C. Jeynes, R.P. Webb, A. Lohstroh, Rev. Acceler Sci. Technol. 4, 41 (2011).

[7] N. Herbots, J.M. Shaw, Q.B. Hurst, M.P. Grams, T.J. Culbertson, D.J. Smith, V. Atluri, P. Zimmerman, K.T. Queeney, Mater. Sci. Eng. B 87, 303 (2001).

[8] R.D. Verda, J.R. Tesmer, M. Nastasi, R.W. Bower, Nucl. Instrum. Methods Phys. Res. B 187, 383 (2002).

[9] R.D. Verda, J.R. Tesmer, M. Nastasi, R.W. Bower, Nucl. Instrum. Methods Phys. Res. B 190, 419 (2002).

[10] M. Mayer, SIMNRA User's Guide, Max-PlanckInstitut für Plasmaphysik, Garching, Germany, http://www2.if.usp.br/ lamfi/guia-simnra.pdf (2012).

[11] J. Jeong, Y. Hong, J.K. Jeong, J.-S. Park, Y.-G. Mo, J. Displ. Technol. 5, 495 (2009).

[12] K. Hozawa, H. Miyazaki, J. Yugami, in: Electron Device Meeting, IEDM'02 Int., IEEE, Piscataway (NJ) 2002, p. 737. 